\title{
Erratum to: Radiation therapy targets and the risk of breast cancer-related lymphedema: a systematic review and network meta-analysis
}

\author{
Simona F. Shaitelman ${ }^{1}$ - Yi-Ju Chiang ${ }^{2}$ Kate D. Griffin ${ }^{2} \cdot$ Sarah M. De Snyder $^{3}$ • \\ Benjamin D. Smith ${ }^{1} \cdot$ Mark V. Schaverien $^{4}$. Wendy A. Woodward ${ }^{1}$. \\ Janice N. Cormier ${ }^{2}$
}

Published online: 9 February 2017

(C) Springer Science+Business Media New York 2017

\section{Erratum to: Breast Cancer Res Treat DOI 10.1007/s10549-016-4089-0}

In the original publication of the article, the co-author names were missed out inadvertently. The corrected author group is given in this erratum. The original article was corrected.

The online version of the original article can be found under doi:10.1007/s10549-016-4089-0.

Simona F. Shaitelman

sfshaitelman@mdanderson.org

1 Department of Radiation Oncology, University of Texas MD Anderson Cancer Center, 1515 Holcombe Blvd, Unit 1202, Houston, TX 77030, USA

2 Department of Surgical Oncology, University of Texas MD Anderson Cancer Center, 1515 Holcombe Blvd, Unit 1484, Houston, TX 77030, USA

3 Department of Breast Surgical Oncology, University of Texas MD Anderson Cancer Center, 1515 Holcombe Blvd, Unit 1434, Houston, TX 77030, USA

4 Department of Plastic Surgery, University of Texas MD Anderson Cancer Center, 1515 Holcombe Blvd, Unit 1488, Houston, TX 77030, USA 